\title{
LAS ACTIVIDADES EMPRESARIALES Y COMERCIALES DE UNA FAMILIA DE ORIGEN FRANCÉS EN COLOMBIA. EL CASO DE LA FAMILIA DEREIX, 1896-1950
}

José Polo Acuña Universidad de Cartagena Colombia 
Panorama Económico, Vol. 27 - No. 4 (Octubre - Diciembre de 2019), pp. 805-833

José Polo Acuña

Las actividades empresariales y comerciales de una familia de origen francés en Colombia. El caso de la familia Dereix, 1896-1950

\title{
Resumen
}

Este trabajo se ocupa de analizar las actividades empresariales y comerciales de una familia de origen francés en el valle del río Sinú (Colombia) en el período 1896-1950, tiempo en el cual desarrollaron labores de producción agrícola y explotación maderera, ganaderia, así como especulaciones relacionadas con tierras, banca, créditos, compra-venta de acciones y bonos en diversas compañías e incursiones en el comercio local. El papel de la familia Dereix fue importante a lo largo de dos generaciones porque su experiencia permite mostrar, por un lado, la manera como el valle del río Sinú se fue orientando hacia el país nacional y la economía mundial a partir de actividades productivas y comerciales que desarrollaron individuos y familias empresariales; por otro lado, el uso creativo que empresarios y comerciantes hicieron del contexto fronterizo para sobreponerse a las adversidades de un mercado permeado por la estrechez, precariedad en las vías de comunicación, limitada tecnología y una débil articulación a la economía mundial.

Palabras clave: Emprendimiento, Conglomerados, comercio

Les activités entrepreneuriales et commerciales d'une famille d'origine française en Colombie. Le cas de la famille Dereix, 1896-1950

\section{Résumé:}

Ce fut un moment où ils ont développé la production agricole et l'exploitation forestière, l'élevage, l'élevage et la vente de bétail, ainsi que les spéculations liées à la terre. En finances, les opérations bancaires, crédits, achat et vente d'actions et d'obligations dans diverses entreprises et incursions dans le commerce local. Le rôle de la famille Dereix a été important sur deux générations. D'un côté, la manière dont une zone frontalière comme la vallée de la rivière Sinú était orientée vers le pays national, puis vers l'économie mondiale à partir d'activités productives et commerciales développées par des particuliers et des familles d'entreprises. Manoeuvrer habilement dans un contexte difficile, l'utilisation créative des hommes d'affaires et des commerçants dans contexte frontalier pour surmonter les adversités d'un marché étroit, dont la précarité des canaux de communication, de la technologie limitée et d'une faible articulation avec l'économie mondiale.

Mots clés: Entrepreneuriat, Conglomérats, commerce

The entrepreneurial and commercial activities of a family of french origin in Colombia. The case of the Dereix family, 1896-1950

\begin{abstract}
It was a time when they developed agricultural production and logging, livestock production, as well as landrelated speculation. In finance, banking, credits, purchase and sale of stocks and bonds in various companies and forays into local commerce. The role of the Dereix family has been important over two generations. On the one hand, the way in which a border area like the Sinú river valley was oriented towards the national country, then towards the world economy from productive and commercial activities developed by individuals and families of companies. Skillfully maneuvering in a difficult context, the creative use of businessmen and traders in a border context to overcome the adversities of a narrow market, including the precariousness of communication channels, limited technology and weak articulation with the global economy.Keywords: Free trade, customs, Panama, fiscal policy.
\end{abstract}

Keywords: Entrepreneurship, Conglomerate, trade 


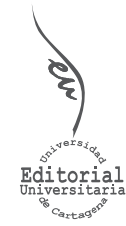

\section{Las actividades empresariales y comerciales de una familia de origen francés en colombia. El caso de la familia dereix, 1896-1950}

INFORMACIÓN DEL ARTíCULO

Recepción del artículo: 03/12/2018

Concepto de evaluación: 01/03/2019

Aceptación del artículo: 03/07/2019

José Polo Acuña

Universidad de Cartagena, Colombia

\section{INTRODUCCIÓN}

En la primera mitad del siglo XIX el valle del río Sinú parece haber sido un espacio olvidado por Cartagena y la joven república de Colombia. Las pocas referencias que se tenían de su territorio se deben a Louis Striffler, un alsaciano que lideró junto a Víctor Dujardin el establecimiento de una compañía minera en el Alto Sinú en 1844 (Striffler, 1922, pp. 5-165; Palacios, 2009, pp. 201-203). Esta situación cambió en la segunda mitad de siglo cuando comerciantes y empresarios de Cartagena vieron en el Sinú la posibilidad de invertir en negocios relacionados con géneros silvícolas, cacao, maderas y ganado, lo cual se convirtió en un respiro ante la crisis de la ciudad amurallada producida por la guerra de independencia y agravada posteriormente por la escasa navegabilidad del canal del Dique que afectó la ya precaria conexión con el río Magdalena (Ripoll, 2002, pp. 219-246, 235) (Calvo, 2002, p. 193) (Restrepo y Rodríguez, 2003, p. 8). Pero al mismo tiempo se fueron creando las condiciones para la formación de un núcleo de comerciantes y empresarios del mismo valle quienes desplegaron sus actividades desde finales del siglo XIX, las cuales

\footnotetext{
1. El río Sinú corre en sentido sur-norte desde su nacimiento, en el Nudo de Paramillo (Antioquia), a $3.500 \mathrm{msnm}$, hasta su desembocadura en la boca de Tinajones en el extremo sur del golfo de Morrosquillo (mar Caribe). Posee una longitud de aproximadamente $340 \mathrm{~km}$. y a lo largo de su curso establece complejas interacciones con caños y quebradas que le tributan sus aguas, así como con ciénagas y zonas pantanosas que reciben sus excesos de agua en tiempos de precipitaciones. El valle del río Sinú comienza en proximidades de la angostura de Urrá, a unos $30 \mathrm{~km}$. de la población de Tierralta, al sur del departamento de Córdoba, corriendo paralelo al río hasta su desembocadura en Tinajones, presentando una anchura promedio de $26 \mathrm{~km}$. hasta Montería, y entre ésta y Lorica unos 60 km. (Mapa 1) (IGAC, 1982, pp. 21-28).
} 
contribuyeron con el dinamismo comercial de poblaciones como Lorica, Cereté, Ciénaga de Oro y Montería. Sus negocios incluyeron cría, venta y compra de ganado, especulación inmobiliaria con compra-venta de tierras y propiedades urbanas, explotación madera, producción y comercialización de cacao, extracción de géneros silvícolas (caucho, tagua, ipecacuana, zarzaparrilla, bálsamo), así como la especulación derivada de operaciones comerciales como giros, letras de cambio, préstamos, hipotecas y adquisición de acciones en la banca. Esta diversificación económica los ubicaba, según la tipificación de Dávila (2013), como negociantes que aprovechaban las ventajas coyunturales ofrecidas por el comercio con las que presentaban los mercados crediticios y las actividades extractivas o productivas (Ocampo, 2013, p. 21). En la segunda mitad del siglo XIX estos comerciantes y empresarios se convirtieron en una "nueva clase" que contribuyó con los procesos de expansión mercantil que dinamizaron las economías regionales (Ocampo, 2013, p. 22).

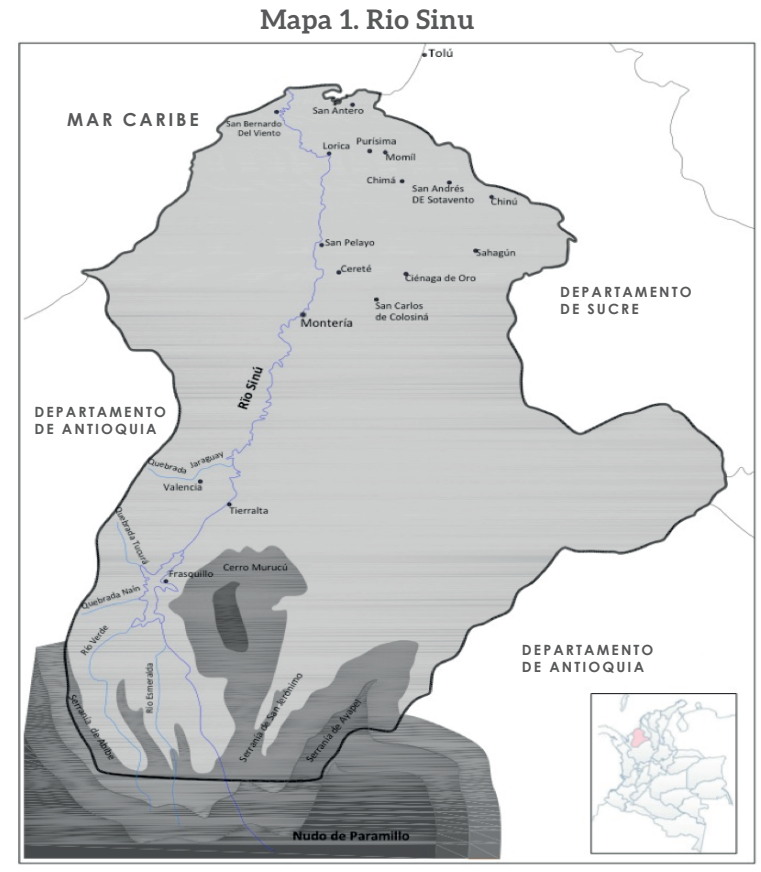

En ese orden de ideas, este trabajo se ocupa de analizar las actividades empresariales y comerciales de la familia Dereix en el valle del río Sinú en el período 18961950, tiempo en el cual desarrollaron labores de producción agrícola, explotación maderera y cría, levante y venta de ganado, así como especulaciones relacionadas con la banca, créditos, compra de acciones y bonos en compañías, y el comercio local.

Fuente: (IGAC, 1992)

El papel de esta familia fue importante porque su experiencia permite mostrar, por un lado, la manera en que un área de frontera como el valle del río Sinú se fue orientando hacia el país nacional a partir de actividades productivas y comerciales que desarrollaron individuos y familias empresariales; por otro, el uso creativo que empresarios y comerciantes hicieron del contexto fronterizo para sobreponerse a las adversidades de un mercado permeado por la estrechez, precariedad de las vías de comunicación, limitada tecnología y una débil articulación a la economía mundial. 
El trabajo está estructurado en tres partes. En la primera se aborda el contexto en el que surgieron comerciantes y empresarios del valle del Sinú, resaltando aspectos asociados con la expansión de la frontera ganadera y agrícola, la adjudicación de baldíos y la relación que se estableció entre comerciantes y empresarios del Sinú con Cartagena. La segunda parte se centra en la llegada de la familia Dereix a Montería, la cual está relacionada con la creación de la Compañía Francesa del Río Sinú, así como con el contexto familiar que posibilitó su asentamiento en el Sinú. La tercera se ocupa de la organización de los negocios de la familia Dereix a través de la creación de la sociedad Octabio \& León Dereix (O. \& L. Dereix), la diversificación de sus inversiones y la lógica que subyació en sus actividades empresariales y comerciales. Esta parte también analiza los negocios de la familia una vez disuelta O. \& L. Dereix, propiciada por el retiro de Octabio Dereix* y la incorporación de los hijos y la esposa de León Dereix.

Las fuentes para la reconstrucción de las actividades económicas de la familia Dereix proceden en su mayor parte del Archivo Histórico de Córdoba (AHCOR), en la ciudad de Montería, particularmente el fondo documental de la Notaría Primera, el cual contiene información ininterrumpida desde 1908, aunque algunas referencias de sus documentos remiten a años anteriores. Este acervo documental contiene escrituras públicas relacionadas con compra-venta de tierras, ganado, producciones agrícolas, silvícolas y madereras, hipotecas, conformación de sociedades de comercio, entre otros, los cuales nos permitieron en gran parte reconstruir la organización de los negocios de los Dereix. Adicionalmente, los documentos notariales aportaron datos sobre nombres, fechas y lugares de procedencia de algunos miembros de la familia. Esta fuente se complementó con la consulta de la prensa de la época de la ciudad de Montería, así como guías comerciales y sociales del Sinú escritas por contemporáneos del período estudiado. No fue posible ubicar otro tipo de fuentes como correspondencia epistolar entre miembros de la familia, libros de contabilidad y testimonios orales de la primera o segunda generación de la familia, los cuales hubiesen sido claves para tener una mirada más completa de la historia de sus actividades económicas ${ }^{2}$.

\section{EL VALLE DEL RÍO SINÚ: DEL "DESIERTO VERDE” A LA FRONTERA DE LAS OPORTUNIDADES}

A mediados del siglo XIX el Sinú despertó el interés de negociantes, empresarios, compañías extranjeras y colonos por sus riquezas naturales representadas en bosques para la explotación maderera (caoba, cedro), géneros silvícolas (bálsamo de tolú, raicilla, caucho) y pastos naturales y "artificiales" (guinea, pará), los cuales potencializaron la diseminación del ganado en una frontera abierta que ofrecía promisoriamente sus tierras para ser ocupadas y laboradas en algún proyecto productivo. No menos importante resultó el eco histórico que en otrora tiempo había hecho del Sinú una región donde las huestes españolas encontraron oro en las tumbas y montículos de la nobleza indígena en el siglo XVI. Así, en 1844 Louis Striffler arribó al Alto Sinú para establecer la Compañía Minera del Río Sinú, en cuya travesía realizó una descripción de lugares y costumbres

\footnotetext{
* A lo largo del texto conservamos los nombres y los apellidos de los miembros de la familia Dereix tal como ellos se firmaban en los documentos notariales consultados en el Archivo Histórico de Córdoba.

2. La investigadora Gloria Isabel Ocampo realizó el 31 de julio de 1985 una entrevista en vida a Carlos Dereix, hijo de León Dereix, en el marco de su investigación sobre la instauración de la ganadería en el valle del río Sinú (2007), a la cual tuvimos acceso con permiso y generosidad de su autora y de los buenos oficios de María Beatriz García Dereix, directora de la Biblioteca Bartolomé Calvo, del Banco de la República- Sucursal Cartagena.
} 
importante para conocer detalles de la vida en la zona en la primera mitad del siglo XIX (Striffler, 1922). En Lorica observó abundancia de víveres a muy bajo costo, y al llegar a Cereté remontando el río llamó su atención la existencia de un astillero donde se fabricaban piraguas; allí vivía un viejo marinero de apellido Flórez, experimentado en el conocimiento del río Sinú, el cual se desplazaba constantemente río arriba al Alto Sinú a cortar madera para construir barquetonas (Striffler, 1922, p. 13). Al llegar a Montería Striffler observó que el pueblo, al igual que Cereté, estaba abrigado de una alta albarrada y tierra que lo protegía de las crecidas del río, con casas de techos pajizos, pintadas de blanco y rodeadas de tupidos naranjales (Striffler, 1922, p. 14).

Al dejar Montería el alsaciano anotó que "[...] tuvimos que decir adiós a la civilización. De allí en adelante ya no había esperanza de encontrar una casa para dormir. Una región inculta, inhabitada, se abrió para nosotros, triste perspectiva para un hombre habituado a las comodidades de la vida" (Striffler, 1922, p. 14). La zona "inculta" e "inhabitada" correspondía al Alto Sinú, llamado por Striffler el "desierto verde", un área boscosa y selvática que para la época aún no había sido afectada por la expansión agrícola-ganadera y la deforestación maderera. Sin embargo, esta zona estaba habitada por una variedad de grupos indígenas, mestizos, negros cimarrones, extranjeros y aventureros que fueron a parar allí huyendo de los controles sociales y aprovechando las oportunidades que ofrecía el medio (Striffler, 1922, p. 22). Bien pronto el desarrollo del comercio en el golfo de Urabá, así como la expansión agrícola y ganadera desde el sur de Cartagena contribuirían a hacer del valle del Sinú un espacio económico dinámico que ofrecería oportunidades para que comerciantes y empresarios desarrollaran sus actividades (Parsons, 1996, pp. 50-54, 82).

En 1879 el agente consular de los Estados Unidos en Cartagena llamó la atención sobre los bosques existentes en los alrededores de Montería, señalando que el cedro y la caoba eran de excelentes calidades susceptibles de ser exportados por la Bahía de Cispata (Parsons, 1952, p. 75). Entre 1883 y 1915 la explotación maderera en el Sinú recibió un impulso de la George D. Emery Company, de Boston, cuyo radio de acción fueron las áreas del valle del Sinú alrededor de Montería y los distritos de Canalete, San Juan y Urabá (American Lumbermen, 1905, p. 21; Parsons, 1952, p. 75). Un estimativo calculó que la Casa Emery exportó anualmente 3.000 toneladas de caoba y cedro, invirtiendo en el país una suma no inferior a $\$ 70.000$ oro anuales; se cree que para 1916 la compañía había dejado en el Sinú alrededor de $\$ 2.000 .000$ oro distribuidos entre empresarios, empleados y trabajadores (Nascimento, 1916, p. 28).

De otra parte, la disponibilidad de tierras propició el establecimiento de haciendas, hatos, fincas y unidades de explotación maderera. En 1881, por ejemplo, se conformó la unidad de explotación llamada Marta Magdalena, cuando el francés Leonce Boiteau obtuvo por concesión 5.440 hectáreas de baldíos, a las cuales se fueron anexando otras propiedades que terminaron de conformar la sociedad civil Cacaotales de Marta Magdalena. En un principio la compañía fue concebida para establecer una plantación de cacao, pero terminó sembrada de pastizales orientada hacia la cría y levante de ganado. En 1882 los ciudadanos belgas Louis y George Verbrugghe adquirieron tierras por concesión de baldíos y compra de posesiones a particulares hasta completar 6.500 hectáreas en 1888, que luego conformarían la compañía franco-belga Sociedad Agrícola del Sinú, con sede en París, dedicada exclusivamente a la cría y engorde de ganado (Ocampo, 2007, pp. 26-27). En 1897 las sociedades francesa y belga -Mosquito y Cacaotales de Marta Magdalena- se fusionaron para crear la Compañía Francesa del Rio Sinú, cuyas actividades se centrarían en la producción de caña, café, coco y ganado, así como la explotación de maderas en 
los predios aportados por los socios. La compañía se inició con un capital de 700.000 francos, con sede en París, cuyos predios estaban situados en la margen izquierda del río Sinú compuesto por unas 12.000 hectáreas, en jurisdicción de Montería (Ocampo, 2007, p. 27-28).

Por otro lado, la expansión ganadera fue propiciada por la demanda de carne de la economía de plantación de caña en Cuba ante la disminución de los hatos por la guerra de los diez años (1869-1878), así como por la construcción del canal de Panamá y la apertura de los mercados antioqueños y santandereanos que venían en crecimiento (Posada, 1998, pp. 179-184; Álvarez, 2016, pp. 20-29; Berrocal, 1980, pp. 117-139). De esta manera se conformaron haciendas, hatos y potreros distribuidos por el Bajo y Medio Sinú, cambiando dramáticamente el paisaje boscoso hacia una inmensa sabana de pastos (Van Ausdal, 2008, p. 62). El valle del río Sinú se constituyó de esta forma en una gran reserva de pastos y ganado con mercados nacionales e internacionales en expansión, lo que contribuyó al despegue económico de una ciudad hasta entonces fronteriza: Montería ${ }^{3}$.

\section{LA LLEGADA DE LA FAMILIA DEREIX A MONTERÍA}

En este contexto de expansión de actividades agrícolas y ganaderas, así como de extracción de géneros silvícolas y explotación maderera arribaron a Montería los hermanos Marie Joseph Charles Leonard Octave Dereix y Marie Joseph François León Dereix entre 1894 y 1897, cuando reemplazaron en la administración de la Compañía Francesa del Río Sinú al señor Emilio Marquet ${ }^{4}$ (Nascimento, 1916, p. 26; Exbrayat, 1939, p. 83; Berrocal, 1980, p. 59; Ocampo, 2007, pp. 27-29).

Octabio Dereix nació el 16 de febrero de 1860 en Mareui-Sur-Belle (Dordogne, Francia) y su hermano León el 16 de junio de 1869; eran hijos de Jules Dereix y Marie Dereix (AHCOR, NPM, EP. 754-755, 1943)5. Octavio y León casaron con ciudadanas francesas, las hermanas Marthe y Marie Carolina Juana Conrad Bruat, las cuales viajaron con ellos al Sinú ${ }^{6}$. Marie y Marthe nacieron el 17 de octubre de 1873 y el 24 de febrero de 1880 respectivamente, en Cherbourq-Mare che, Francia; eran hijas de Alfredo Conrad y Ana Bruat (AHCOR, NPM, EP. 754, 1943). Contaba Carlos Dereix, hijo de León Dereix, que al retirarse de la administración de la Compañía Francesa en 1906, su tío Octabio y su padre León invirtieron sus capitales en propiedades rurales y urbanas, así como en negocios de maderas, ganado y el cultivo de cacao (Ocampo, 1985, p. 17). Es probable que antecedentes familiares también aseguraran a los hermanos Dereix disponibilidad de recursos que quizá al principio emplearon en su establecimiento en el Sinú. Su padre Jules Dereix, nacido en 1828 en Leguillac de Cercles, Dordogne, fue recaudador de finanzas y miembro del Concejo General de esa comarca francesa, lo cual le colocaba en una posición de reconocimiento y prestancia social y política.

\footnotetext{
3. En 1798 Montería fue elevada a la categoría de parroquia y en 1804 a la de villa. En 1840 se convirtió en cabecera de distrito y en 1910 era la cabecera de la provincia del Alto Sinú, para surgir después como capital del municipio de Montería en 1923 y capital del departamento de Córdoba en 1951 (Exbrayat, 1994, p. 14).

4. Según cuenta Carlos Dereix, varios socios de la Compañía Francesa del Río Sinú eran parientes de su tío y de su padre, gente acaudalada que tenía influencia en la empresa. Adicionalmente, el gerente de la compañía en Francia era primo de su padre León Dereix (Ocampo, 1985, pp. 2,35).

5. AHCOR: Archivo Histórico de Córdoba. NPM: Notaría Primera de Montería. E.P.: Escritura pública.

6. Para una genealogía de la familia Dereix en el Sinú cf. "Los franceses en el Sinú. "Los Dereix Conrad. Parte 2 (2014)". Disponible en:

http://lacomarcadelsol.wordpress.com/2014/08/16/franceses-en-el-sinu-los-dereix-conrad-parte-1/
} 
Por su parte, el padre de las hermanas Marie Caroline y Marthe Conrad-Bruat, Alfred Conrad, fue un militar que recibió la distinción de la Legión de Honor en el grado de Gran Oficial, en 1888, y tuvo los grados de vice-almirante, comandante en jefe y prefecto marítimo de Lorient, Morbihan7. Por otro lado, Octabio Dereix, residenciado ya en Montería, Colombia, junto a su esposa Marie Conrad Bruat, otorgaron en 1908 poder especial en Francia a Marie Joseph Etienne Charles Dereix, hermano de Octavio, quien era capitán de infantería, para que en representación de su cuñada Marie Conrad recibiera del señor Luis Bassy, notario de París, la suma de 5.000 francos heredados de su padrino el banquero Charles Joseph Soulange Renard (AHCOR, NPM, EP. 73, 1908.). El que el padre de los hermanos Octabio y León Dereix fuera una persona influyente y otro hijo suyo en París fuera capitán de infantería, y que el padre de las hermanas Conrad Bruat también fuera un reconocido militar, nos sugiere que los Dereix-Conrand provenían de reconocidas familias con prestancia económica y social. De otra parte, las relaciones de compadrazgo que probablemente los padres de Marie Conrad Bruat establecieron con personalidades como el banquero Soulange, reafirman la prestancia de su círculo familiar y social.

La vida de la familia Dereix en el Sinú no supuso la ruptura con su país natal, antes por el contrario reafirmaron sus valores culturales mediante el uso de la lengua francesa al interior de su círculo familiar y en la educación inicial de sus hijos. Así lo manifestó Carlos Dereix al contar que sus padres contrataron a la institutriz Gabriela Goné para que lo instruyera en sus primeros años antes de emprender su formación con los hermanos Lasallistas en Bogotá (Ocampo, 1985, p. 7). Adicionalmente, los miembros de la familia viajaban a Francia con cierta regularidad: el consulado de Colombia en Burdeos registró en 1934 el pasaporte visado de Octabio Dereix, quien viajaba en el vapor "Cuba" rumbo a Cartagena, y de
Figura 1. Octabio Dereix. Fotografía de pasaporte, Burdeos, 1934

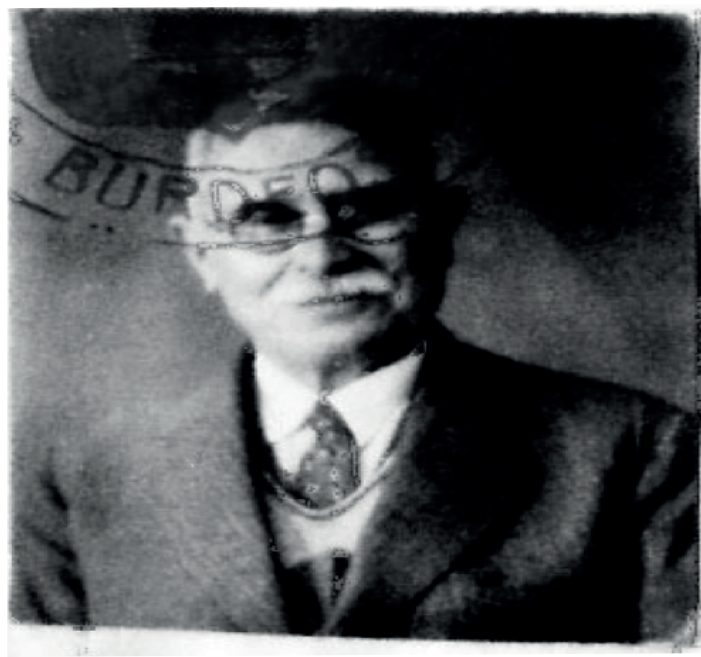

Fuente: "Franceses en el Sinú: Los Dereix Conrad. Parte 1". Recuperado en

https://lacomarcadelsol.wordpress.com/category/apellido-dereix/

\footnotetext{
7. "Los franceses en el Sinú: Los Dereix Conrad. Parte 1 (2014)". Disponible en https://lacomarcadelsol.wordpress. com/category/apellido-dereix/.4. Según cuenta Carlos Dereix, varios socios de la Compañía Francesa del Río Sinú eran parientes de su tío y de su padre, gente acaudalada que tenía influencia en la empresa. Adicionalmente, el gerente de la compañía en Francia era primo de su padre León Dereix (Ocampo, 1985, pp. 2,35).
} 
allí hacia Montería para encontrarse con su hermano León. En el registro de visado se lo describió como un hombre de 68 años de edad, estatura de 1.85 metros, de color blanco, ojos castaños, complexión robusta y de ocupación "agricultor" (Figura1). A su esposa Marie se la detalló como una mujer de 60 años, estatura de 1.65 metros, ojos azules, piel blanca y de complexión robusta ${ }^{8}$. En otra oportunidad, en 1940, el consulado de Colombia en Panamá registró la salida de Octabio Dereix, quien iba con su esposa rumbo a Montería, describiendo su oficio como hacendado?.

Los Dereix se acomodaron rápidamente a la vida del trópico sinuano quizá por la experiencia que habían tenido en otros lugares de similar ambiente. Antes de arribar al Sinú León Dereix (Figura 2), por ejemplo, había prestado sus servicios militares en Túnez, Argelia y Senegal, lo que probablemente facilitó su adaptación a la región y sus gentes (Ocampo, 1985, p. 2). Ello se reflejaría posteriormente en el trato que Carlos Dereix daba a sus empleados, resaltando lo justo como base de las buenas relaciones en su hacienda El Torno de Matamoros:

Figura 2. León Dereix, ca. 1920

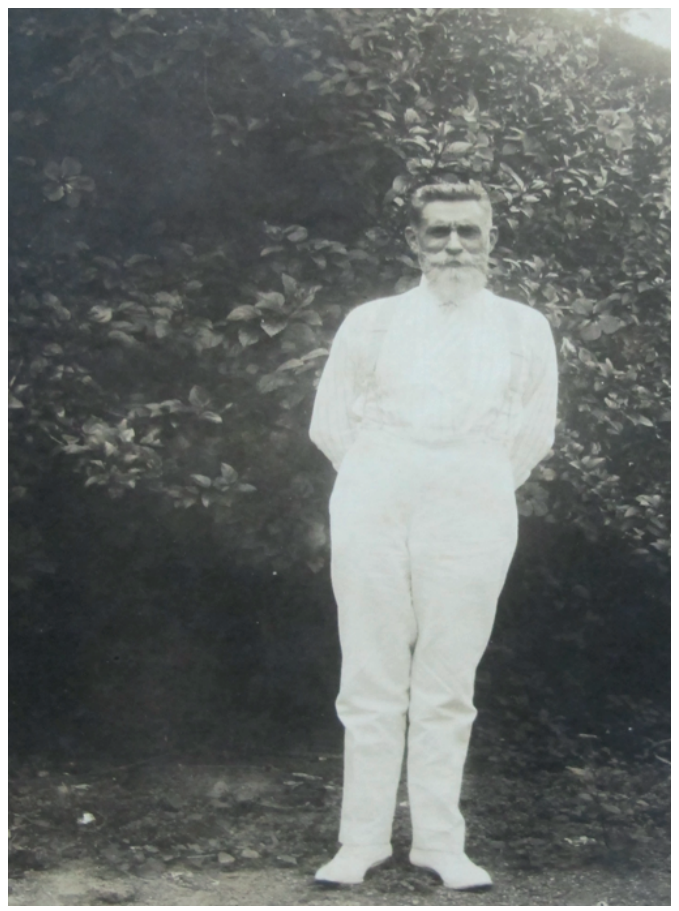

"Nosotros desde un principio justamente tuvimos buen trato con los trabajadores debido a nuestra instrucción justamente francesa, no abusamos de ellos nunca, siempre fueron considerados justamente como buenos trabajadores, tanto así que yo he tenido trabajadores que me han trabajado desde alrededor de treinta, treinta y cinco y cuarenta años y la mayor parte trabajaron diez, doce, quince, veinte años conmigo" (Ocampo, 1985, pp. 23-24).

La vida de los hermanos Dereix en Montería fue austera, pues contaba el mismo Carlos Dereix que al llegar su padre a la finca El Torno de Matamoros, una vez casado con

Fuente: Archivo fotográfico de la familia Dereix, Centro de Documentación Regional Orlando Fals Borda, Banco de la República, Montería.

8. “Los franceses en el Sinú. Los Dereix Conrad. Parte 2 (2014)”. Recuperado en: http://lacomarcadelsol.wordpress. com/2014/08/16/franceses-en-el-sinu-los-dereix-conrad-parte-2/

9. "Los franceses en el Sinú. Los Dereix Conrad. Parte 2 (2014)". Recuperado en: http://lacomarcadelsol.wordpress. com/2014/08/16/franceses-en-el-sinu-los-dereix-conrad-parte-2/ 
Marthe Conrad, la casa que construyeron era de madera, con techo pajizo y sin piso; sólo hasta 1943 la vieja casa fue demolida porque el río la estaba consumiendo por una de sus esquinas, dando paso a una nueva vivienda con piso y mayores comodidades para la familia que comenzaba a aumentar (Ocampo, 1985, p. 26). que Carlos Dereix daba a sus empleados, resaltando lo justo como base de las buenas relaciones en su hacienda El Torno de Matamoros:

\section{LA ORGANIZACIÓN DE LAS ACTIVIDADES EMPRESARIALES Y COMERCIALES DE LOS HERMANOS DEREIX}

La experiencia que adquirieron los hermanos Dereix en la administración de la Compañía Francesa del Río Sinú les permitió familiarizarse con el ambiente de la ciudad de Montería, es decir con gentes, lugares y potenciales actividades económicas en las que podían incursionar. Pronto desplegaron sus habilidades de negociantes para la compra y venta de tierras; cría, levante, ceba y venta de ganado; producción de cacao; extracción de madera; comercio local y operaciones especulativas alrededor de captación legal de depósitos, créditos hipotecarios sobre bienes o producción agrícola, adquisición de derechos de deudas y compra de acciones en compañías varias y la banca.

\subsection{La adquisición de tierras}

Desde la segunda mitad del siglo XIX el valle del río Sinú fue un espacio apetecido por empresarios, colonos y comunidades campesinas por la fertilidad de sus suelos, lo cual propició requerimientos para el otorgamiento de baldíos. La jurisdicción de Montería y en general la banda occidental del río Sinú fue un área de particular atención: 17 individuos recibieron 44.243 hectáreas de baldíos que, según cálculos de Tovar representaron el 76\% de las tierras adjudicadas en el último cuarto del siglo XIX (Tovar, 1997, p. 41). LeeGrand (2016, pp. 285-287), muestra como entre 1870 y 1931 se otorgaron 230.577 hectáreas de baldíos repartidas en 184 concesiones (Tabla 1.).

Tabla 1.

Concesiones de tierras baldías en el valle del río Sinú 1870-1931

\begin{tabular}{|c|c|c|c|c|c|c|c|}
\hline & \multicolumn{2}{|c|}{$1870-1900$} & \multicolumn{2}{|c|}{ 1901-1917 } & \multicolumn{2}{|c|}{ 1918-1931 } & \\
\hline Municipio & $\begin{array}{c}\mathrm{N}^{\circ} \\
\text { concesiones }\end{array}$ & $\begin{array}{c}\mathrm{N}^{\circ} \text { de } \\
\text { hectáreas }\end{array}$ & $\begin{array}{c}\mathrm{N}^{\circ} \\
\text { concesiones }\end{array}$ & $\begin{array}{c}\mathrm{N}^{\circ} \text { de } \\
\text { hectáreas }\end{array}$ & $\begin{array}{c}\mathrm{N}^{\circ} \\
\text { concesiones }\end{array}$ & $\begin{array}{c}\mathrm{N}^{\circ} \text { de } \\
\text { hectáreas }\end{array}$ & $\begin{array}{c}\text { TOTALES } \\
\text { HECTAREAS }\end{array}$ \\
\hline $\begin{array}{c}\text { Ciénaga } \\
\text { de Oro }\end{array}$ & 1 & 4.986 & & & & & 4.986 \\
\hline Cereté & & & & & 4 & 8.074 & 8.074 \\
\hline Lorica & 1 & 533 & 7 & 9.303 & 20 & 9.269 & 19.105 \\
\hline Montería & 32 & 62.344 & 41 & 41.959 & 48 & 47.571 & 151.874 \\
\hline
\end{tabular}


Tabla 1.

Concesiones de tierras baldías en el valle del río Sinú 1870-1931

\begin{tabular}{|c|c|c|c|c|c|c|c|}
\hline & \multicolumn{2}{|c|}{$1870-1900$} & \multicolumn{2}{|c|}{$1901-1917$} & \multicolumn{2}{|c|}{$1918-1931$} & \\
\hline Municipio & $\begin{array}{c}\mathbf{N}^{\circ} \\
\text { concesiones }\end{array}$ & $\begin{array}{c}\mathbf{N}^{\circ} \text { de } \\
\text { hectáreas }\end{array}$ & $\begin{array}{c}\mathbf{N}^{\circ} \\
\text { concesiones }\end{array}$ & $\begin{array}{c}\mathbf{N}^{\circ} \text { de } \\
\text { hectáreas }\end{array}$ & $\begin{array}{c}\mathbf{N}^{\circ} \\
\text { concesiones }\end{array}$ & $\begin{array}{c}\mathrm{N}^{\circ} \text { de } \\
\text { hectáreas }\end{array}$ & $\begin{array}{c}\text { TOTALES } \\
\text { HECTAREAS }\end{array}$ \\
\hline $\begin{array}{l}\text { Puerto } \\
\text { Escondido }\end{array}$ & & & 6 & 14.823 & 2 & 5.000 & 19.823 \\
\hline Sahagún & 1 & 2.754 & & & & & 2.754 \\
\hline $\begin{array}{c}\text { San } \\
\text { Carlos }\end{array}$ & 2 & 2.627 & 1 & 3.176 & & & 5.803 \\
\hline $\begin{array}{l}\text { San } \\
\text { Pelayo }\end{array}$ & 1 & 3.979 & & & 15 & 7.980 & 11.959 \\
\hline $\begin{array}{c}\text { Sinú } \\
\text { [Chinú ] }\end{array}$ & 2 & 6.199 & & & & & 6.199 \\
\hline TOTALES & 40 & 83.422 & 55 & 69.261 & 89 & 77.894 & 230.577 \\
\hline
\end{tabular}

Fuente: LeeGrand, 2016, pp. 285-287.

Como se observa, la jurisdicción de Montería en la muestra aportada por LeeGrand durante los 61 años que cubre el período, ocupó el primer lugar en el número de hectáreas adjudicadas (66\%), seguida de lejos por Puerto Escondido -área costera- (9\%), Lorica (8\%), San Pelayo (5\%), Cereté (4\%), Sinú [Chinú] (3\%), Ciénaga de Oro (2\%) y Sahagún (1\%). El número de hectáreas adjudicadas no era proporcional al número de concesiones, pues una sola de estas podía abarcar una gran extensión de tierras que en ocasiones oscilaba entre 3.000 y 5.000 hectáreas (Tovar, 1997, p. 42).

Los hermanos Octabio y León Dereix adquirieron a través de O. \& L. Dereix un total de 5.152 hectáreas de baldíos: 3.159 en 1912 y 1.993 en $1923^{10}$. Una muestra de 27 transacciones de tierras realizadas por ellos entre 1908 y 1926 permite afirmar que sus adquisiciones estaban ubicadas en un amplio espacio del valle del río Sinú que comprendían las bandas occidental y oriental del río, el Alto Sinú (Tierra Alta y La Angostura) y poblaciones satélites de Montería como San Carlos de Colosiná (Tabla 2).

10. Centro de Documentación Orlando Fals Borda, Banco de la República, sucursal Montería, Colección Fals Borda, Caja 03, Carpeta 07. También cf. (Ocampo,1985, p. 12) 
Tabla 2

Algunas propiedades adquiridas por O. y L. Dereix 1908-1926

\begin{tabular}{|c|c|c|c|}
\hline Año de adquisición & Propiedad & Vendedor & Valor \\
\hline 1908 (9- marzo) & $\begin{array}{l}25 \text { fanegadas de } \\
\text { tierra (San Carlos) }\end{array}$ & Cornelio Montes & $\$ 300$ oro \\
\hline 1909 (6- julio) & $\begin{array}{c}\text { Posesión rural } \\
\text { ubicada en Santa Ana } \\
\text { (margen occidental } \\
\text { del río Sinú) }\end{array}$ & Ramón J. Bru & $\$ 1.770,60$ oro \\
\hline 1909 (17- julio) & $\begin{array}{c}\text { Finca ubicada } \\
\text { en Santa Ana } \\
\text { (margen occidental } \\
\text { del río Sinú) }\end{array}$ & Ernesto Rosales & $\$ 2.000$ oro \\
\hline 1910 (30- julio) & $\begin{array}{l}\text { Finca El Cabrero } \\
\text { (sembrada en pasto) }\end{array}$ & Santiago Zúñiga & $\$ 500$ oro \\
\hline 1910 (27- agosto) & Finca Ceiba Quemada & Teodoro Casarrubia & $\$ 466,90$ \\
\hline 1911 (9- enero) & $\begin{array}{c}\text { Finca } \\
\text { (sembrada en pasto) } \\
\text { ubicada en } \\
\text { Cerrito Pelado }\end{array}$ & Eusebio Ríos & $\begin{array}{l}\$ 4.000 \\
\text { moneda } \\
\text { nacional }\end{array}$ \\
\hline 1911 (28- enero) & $\begin{array}{c}\text { Hacienda El Torno } \\
\text { de Matamoros }\end{array}$ & José W. Gulfo & $\$ 1.800$ oro \\
\hline 1911 (13 - diciembre) & $\begin{array}{c}\text { Fincas Pirú y } \\
\text { Mazamorra }\end{array}$ & Asías Hermanos & $\$ 2.000$ oro \\
\hline 1913 (12-febrero) & $\begin{array}{c}\text { Finca } \\
\text { Santa Ana (Alto Sinú) }\end{array}$ & $\begin{array}{l}\text { Evaristo Calonje, } \\
\text { Cecilio Calonje, } \\
\text { José L. Padrón }\end{array}$ & $\$ 2.320$ oro \\
\hline 1914 (7 - noviembre) & $\begin{array}{l}\text { Finca ubicada } \\
\text { en El Progreso }\end{array}$ & Eligio del Castillo & $\$ 3.000$ oro \\
\hline
\end{tabular}


Tabla 2

Algunas propiedades adquiridas por O. y L. Dereix 1908-1926

\begin{tabular}{|c|c|c|c|}
\hline Año de adquisición & Propiedad & Vendedor & Valor \\
\hline 1915 (17- septiembre) & $\begin{array}{l}\text { Finca Respirar, } \\
\text { ubicada en } \\
\text { Mazamorra }\end{array}$ & Joaquín Crespo & $\$ 408$ oro \\
\hline 1915 (12- octubre) & $\begin{array}{c}\text { Posesión } \\
\text { La Cantaleta }\end{array}$ & $\begin{array}{l}\text { Rafael Gómez } \\
\text { Martínez }\end{array}$ & $\$ 2.120$ oro \\
\hline 1916 (2 - septiembre) & Posesión rural & $\begin{array}{l}\text { Antonino } \\
\text { Lacharme }\end{array}$ & $\$ 1.500$ oro \\
\hline 1918 (10- agosto) & $\begin{array}{c}\text { Finca } \\
\text { (sembrada de pasto) }\end{array}$ & Cristóbal Rosso & $\$ 800$ oro \\
\hline 1918 (6- septiembre & $\begin{array}{c}\text { Tres (3) fincas } \\
\text { llamadas La Carrizola, } \\
\text { Los Moncholos y } \\
\text { Las Balzas }\end{array}$ & $\begin{array}{l}\text { Luis Amín y } \\
\text { Luis Amín y } \\
\text { Compañía }\end{array}$ & $\$ 1.100$ oro \\
\hline 1919 (28- junio) & $\begin{array}{l}\text { Predios México } \\
\text { y San Salvador }\end{array}$ & $\begin{array}{c}\text { Manuel } \\
\text { Francisco Berrio }\end{array}$ & $\$ 1.000$ oro \\
\hline 1919 (1- septiembre) & $\begin{array}{c}\text { Dos (2) fincas y } \\
\text { un globo de terreno } \\
\text { ubicados en Tierra Alta } \\
\text { y Montería }\end{array}$ & Luis Amín & $\$ 1.300$ oro \\
\hline 1920 (21 -septiembre) & $\begin{array}{l}\text { Lote de terreno llamado } \\
\text { Morocoquiel ubicado } \\
\text { en la banda oriental } \\
\text { del río Sinú }\end{array}$ & Antonino Lacharme & $\$ 2.500$ oro \\
\hline 1921 (7- enero) & $\begin{array}{l}\text { Dos (2) lotes de terreno } \\
\text { llamados San Sebastián y } \\
\text { Santa Ternera, ubicados en } \\
\text { La Angostura, Alto Sinú }\end{array}$ & $\begin{array}{c}\text { Lorenzo } \\
\text { Mercado Barrera }\end{array}$ & $\$ 2.000$ \\
\hline
\end{tabular}


Tabla 2

Algunas propiedades adquiridas por O. y L. Dereix 1908-1926

\begin{tabular}{|c|c|c|c|}
\hline Año de adquisición & Propiedad & Vendedor & Valor \\
\hline 1922 (22- julio) & Finca Pasacaballos & $\begin{array}{c}\text { Justa Herrera } \\
\text { de Falco, José Isabel, } \\
\text { José Salomé y } \\
\text { Petrona Falco }\end{array}$ & $\$ 120$ oro \\
\hline
\end{tabular}

1922 (16 - noviembre)

Potrero Jaraguay

Cristóbal Rosso

$\$ 3.780$ oro

1923 (20- enero)

Varias fincas ubicadas en las mancomunidades

Manuel Jiménez

$\$ 3.750$ oro de Negrete y Hamaca

1923 (14- junio)

Finca en el punto Los Cacaos

Santos Guerra

$\$ 500$ oro

Una huerta

Antonio Sánchez

$\$ 700$ oro

1924 (7- marzo)

Finca Las Balsas

Fernando Del Río

$\$ 200$ oro

Finca El Paraíso

José Higinio Reyes

$\$ 100$ oro

1926 (23-diciembre)

Finca El Carmen

(Angostura)

Adolfo Held

$\$ 150$ oro

Fuente: (AHCOR, NPM, E.P. 54, 1908) (AHCOR, NPM, EP. 150, 1909) (AHCOR, NPM, EP. 179, 1909) (AHCOR, NPM, EP. 127, 1910) (AHCOR, EP. 140, 1910) (AHCOR, NPM, EP. 9, 1911) (AHCOR, NPM, EP. 22, 1911) (AHCOR, NPM, EP. 150, 1911) (AHCOR, NPM, EP. 43,1913) (AHCOR, NPM, EP. 345, 1914) (AHCOR, NPM, EP. 257, 1915) (AHCOR, NPM, EP. 291, 1915) (AHCOR, NPM, EP. 265, 1916) (AHCOR, NPM, EP. 325, 1918) (AHCOR, NPM, EP. 370, 1918) (AHCOR, NPM, EP. 310, 1919) (AHCOR, NPM, EP. 459, 1919) (AHCOR, NPM, EP. 635, 1920) (AHCOR, NPM, EP. 6, 1921) (AHCOR, NPM, EP. 209, 1922) (AHCOR, NPM, EP. 342, 1922) (AHCOR, NPM, EP. 27, 1923) (AHCOR, NPM, EP. 238, 1923) (AHCOR, NPM, EP. 398, 1923) (AHCOR, NPM, EP. 70, 1924) (AHCOR, NPM, EP. 439, 1926) (AHCOR, NPM, EP. 454, 1926). 
De las propiedades registradas en la tabla 2 sobresale El Torno de Matamoros, convertida en la unidad productiva más importante de las actividades empresariales agropecuarias de los hermanos Dereix. Inicialmente fue adquirida de José W. Gulfo a través de un proceso que implicó dos compras con pactos de retroventa por valor de 120 y 800 pesos oro respectivamente, y la adquisición definitiva en 1911 por 1.800 pesos. Contaba Carlos Dereix que cuando se adquirió El Torno éste tenía unas 12 hectáreas de potreros, lo demás correspondía a terrenos incultos de "montaña" (1985, p. 12). Poco a poco la propiedad se fue expandiendo gracias a la adjudicación de baldíos por parte del gobierno y la compra que se hizo a colonos y pequeños finqueros, llegando a ocupar unas 6.100 hectáreas (v. Figura 3).

\section{Figura 3. Construcción de puente en El Torno de Matamoros, c. 1928}

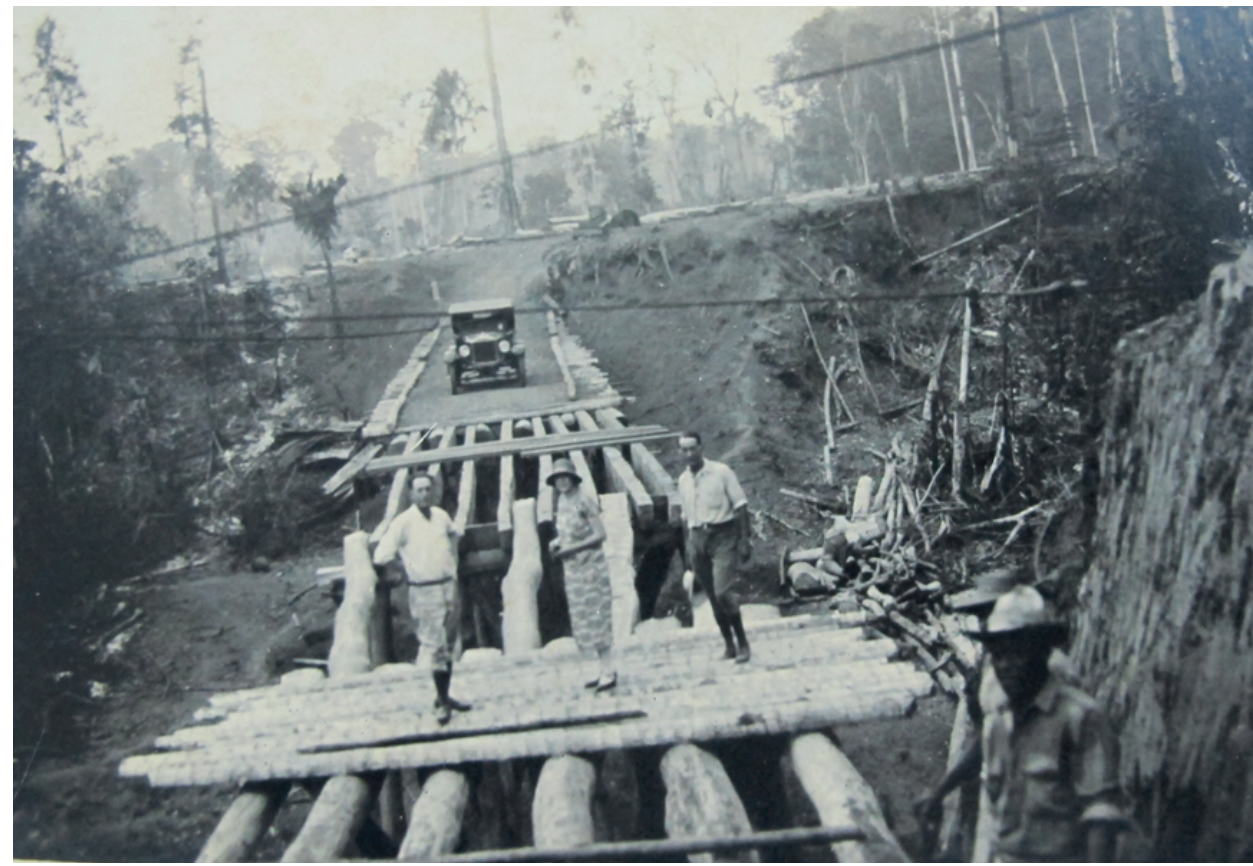

Fuente: Archivo fotográfico de la familia Dereix, Centro de Documentación Regional Orlando Fals Borda, Banco de la República, Montería.

Los Dereix lucharon contra la naturaleza para hacer de El Torno una unidad productiva conectada con el río, abriendo caminos y construyendo puentes en medio de los terrenos cenagosos del Sinú. Carlos Dereix afirmó que "[...] nosotros entonces hicimos también penetración a la finca con buena calzada, puente de concreto, teníamos buldozer, camión, tractor, arado, máquina para fumigar, todo el equipo necesario" (Ocampo, 1985, p. 12). Podría afirmarse que los hermanos Dereix fueron pioneros en la tecnificación del campo con fines empresariales en el valle del río Sinú como veremos más adelante. 
Otras propiedades como las fincas Pasacaballo, Respirar y Pasatiempo fueron conservadas por la familia Dereix como activos que fueron aportados en posteriores sociedades comerciales. Las dos primeras estaban ubicadas en el Alto Sinú, a una distancia de unos 25 o 30 kilómetros del actual municipio de Tierra Alta, y la tercera en cercanías de Montería. Pasacaballo tenía una extensión superficiaria de 4.000 hectáreas, Respirar 100 y Pasatiempo 173 (AHCOR, NPM, EP. 220, 1939.). La ubicación de los predios registrados en la tabla 2 nos permite entonces identificar una probable articulación funcional entre grandes propiedades situadas en el Alto Sinú (El Torno y Pasacaballo), productoras de ganado, géneros agrícolas y madereros, y pequeñas propiedades en el Medio Sinú cercanas a Montería, las cuales probablemente funcionaron como estaciones intermedias consistentes en potreros y centros de abastecimiento de la producción que finalmente era conducida hasta Montería.

\subsection{Actividades ganaderas}

La ganadería fue una de las actividades empresariales más importantes de los hermanos Dereix. Nascimento anotó que

"El Torno de Matamoros es una de las más pintorescas y bien cuidadas haciendas de la región. Pastan allí numerosos rebaños de ganado vacuno de la mejor clase que se conoce por aquí, porque en su labor de selección los Sres. Dereix son incansables. Para mejorar la raza han importado sementales extranjeros. El Torno cría reses finas de buena estampa, muy apreciadas en el mercado; algunos toros de tipo normando llaman la atención de los expertos por su notable desarrollo" (1916, p. 26).

Contrario quizá a la tendencia de la mayoría de haciendas y hatos del Sinú que se dedicaron mayormente al levante, comprando el ganado de cría en otras áreas como Sincelejo o Corozal, los Dereix se inclinaron más por la cría, promoviendo en El Torno los cruces raciales para mejorar la calidad del ganado, aplicando una cuidadosa organización de los procesos de selección. Carlos Dereix afirmó que aunque se hicieron cruces con otras razas, como por ejemplo la Red-Polled, su especialidad se centró en el Romosinuano, una raza resistente al clima tropical y productora de leche y carne de buena calidad. Los sementales eran mantenidos en pesebreras, con poca movilidad; las vacas eran llevadas allí cuando entraban en etapa reproductiva, y sobre ellas se llevaba un registro detallado que permitía establecer con claridad la genealogía y el control de las crías (Ocampo, 1985, p. 30).

La hacienda ganadera de cría demandaba más funciones que una de levante o engorde, por eso El Torno llegó a tener, según cálculos de Carlos Dereix, 60 trabajadores, 6 vaqueros y 6 capataces, además de un bodeguero que administraba las herramientas para el trabajo diario(Ocampo, 1985, p. 29)11. Los trabajadores eran en casi todos oriundos del Sinú, de poblaciones como Sahagún, Ciénaga de Oro, Cereté y San Carlos de Colosiná, los cuales tenían renombre por su capacidad para el trabajo duro, en parte por su experiencia en el proceso de colonización del Alto Sinú desde mediados del siglo XIX (Berrocal, 1980,

11. En la hacienda Marta Magdalena, contemporánea de El Torno, Ocampo identificó los oficios de picador, sembrador, hachero, alambrero, barrero, aserrador, vaquero, mochilero y raspador -el que limpiaba a machete la tierra cultivada-, además de los oficios individuales de bodeguero y carpintero (Ocampo, 2007, 123). 
p. 209). La administración general de la hacienda era ejercida directamente por los hermanos Octabio y León Dereix, lo cual redundó en un estricto control de las actividades productivas.

El mercado de la producción ganadera de El Torno fue el departamento de Santander, particularmente Bucaramanga, que requirió ganado de cinco años de edad en adelante; precisamente por eso la producción no se orientó hacia el mercado antioqueño, el cual demandó ganado entre tres años y medio y cuatro años de edad, es decir, de levante o medianamente gordo ${ }^{12}$. Carlos Dereix relata como los compradores santandereanos adquirían los lotes de ganado para transportarlos en pie hasta el puerto fluvial de Magangué(Yatí), y de allí río arriba hasta los puertos del Magdalena Medio santandereano (Ocampo, 1985, p. 28).

La expansión de las actividades ganaderas en El Torno propiciaron la asociación de los hermanos Dereix con otros ganaderos de la región para crear sociedades comerciales y tener una presencia más fuerte en el mercado. Así, se asociaron en 1917 con Raúl Piñeres y J.W. Gulfo para crear la Compañía Júpiter, dedicada a la producción y comercialización de ganado, cuya duración era de diez años prorrogables, con capital inicial de 12.000 pesos oro americano (AHCOR, NPM, EP. 372, 1917). Aunque no se encontraron documentos del posterior desempeño de esta sociedad, el compromiso de los hermanos Dereix con el desarrollo empresarial agrícola-ganadero fue palpable: en 1929 crearon junto a Lilí Méndez, José Flores, Antonio Sánchez y José María Vivero el Centro Ganado Agrícola, una organización privada para "Representar y defender, por los medios a su alcance, los intereses de los ganaderos y agricultores asociados" (AHCOR, NPM, EP. 52, 1929). Es probable que el Centro de Ganado Agrícola hiciera frente a problemas relacionados con la lenta introducción de pastos artificiales, el desigual cercamiento de potreros con alambre de púas y el lento cruce del ganado con nuevas razas (Burgos, 2000, pp. 58-59) (Van Ausdal, 2008, p. 67).

Figura 4. Aviso comercial

En otras dimensiones del oficio ganadero, los hermanos Dereix actuaron como agentes comerciales en Montería para la venta y distribución de medicinas y vacunas para el ganado, a las cuales acudieron no pocos ganaderos de la región solicitando las vacunas líquidas Pasteur, traídas de Francia para combatir las enfermedades del carbunco y la rabia (V. Figura 4.).

\section{A los Ganaderos}

Vacune Ud. sus ganados con las vacunas liquidas Pasteur de fama mundial; preparadas (n) el Instituto de su mismo nombre en Paris por el sabio más grande del siglo XIX, Luis Pasteur y que mejores resultades prácticos han dado. Agente en Montería José Velásquez Q. Sub-agentes O. \& L DEREIX.

Fuente: (Fiat- Lux, p. 3, enero 9 de 1927)

12. Eugenio Quintero Acosta (1922, sp.), afirmó que el municipio de Montería poseía unas 75.000 hectáreas de terrenos cultivados con pastos, los cuales sostenían unas 110.000 reses vacunas, de las cuales unos 10.000 novillos y varios centenares de vacas se vendían en Antioquia y Santander. Para el análisis de la introducción del ganado costeño a Antioquia cf. (Bonet, 1999, pp.48-56) (Álvarez, 2016, 185-186). 
Con la partida hacia Francia de Octabio Dereix en 1928, éste, por intermedio de su apoderado en Montería Luis Lacharme, se separó legalmente de la sociedad O \& L. Dereix e ingresó Carlos Dereix, hijo de León, aunque la razón social continuó con el mismo nombre por algún tiempo (AHCOR, NPM, EP. 209 y 214, 1928). En 1930 León y Carlos Dereix prorrogaron por diez años más la sociedad en la que aparece este último aportando un capital de 1.000 pesos oro (AHCOR, NPM, EP. 242, 1930). En 1939 O. \& L. Dereix finalizó su existencia legal y en ese mismo año León Dereix junto a sus hijos Carlos, Juan, Luis y Andrés conformaron la sociedad León Dereix e Hijos, cuyas actividades giraron en torno al "Levante, engorde y en general compra y venta de ganado, y todo acto lícito" (AHCOR, NPM, EP. 198, 1939) (AHCOR, NPM, EP. 220, 1939). La sociedad tendría una duración de 10 años prorrogables y un capital inicial de 225.419.61 pesos oro, más las propiedades que se observan en la tabla 3.

Tabla 3

\section{Propiedades del capital inicial de León Dereix e Hijos (1939)}

\begin{tabular}{|c|c|c|}
\hline Propiedad & Extensión & Avalúo o valor estimado \\
\hline El Torno de Matamoros & 6.000 hectáreas & $\$ 180.000$ oro \\
\hline Hacienda "Pasatiempo" & 173 hectáreas & $\$ 25.000$ moneda corriente \\
\hline Finca "Pasacaballos" & 4.000 hectáreas & $\$ 20.000$ moneda corriente \\
\hline Finca "Respirar" & 100 hectáreas & $\$ 2.500$ moneda corriente \\
\hline 1 casa- lote & - & $\$ 20.000$ moneda corriente \\
\hline 1 casa de madera y zinc-lote & - & $\$ 5.000$ oro \\
\hline
\end{tabular}

Fuente: AHCOR, NPM, EP. 220, 1939.

Los socios también contribuyeron con bienes muebles representados en semovientes de diferentes clases, edades y valores (v. Tabla 4), lo que reafirma que la ganadería fue una de las actividades empresariales más importantes de la familia Dereix. Los semovientes aportados a la nueva sociedad recogieron más de dos décadas de tradición en la producción ganadera. 
Tabla 4

\section{Semovientes aportados por los socios de León Dereix e Hijos}

\begin{tabular}{ccc}
\hline Semovientes & Edades & Avalúo \\
\hline 1.211 novillos & Cuatro años & $\$ 58.490,43$ \\
\hline 1.589 novillos & Diversas & $\$ 40.458$ \\
\hline $\begin{array}{c}1.957 \text { reses hembras } \\
\text { (vacas y novillas) }\end{array}$ & Diversas & $\$ 30.332$ \\
\hline 114 novillos & Cinco años & $\$ 4.281,15$ \\
\hline 100 bestias & & $\$ 4.085$ \\
\hline (caballos, mulas y burros) & Diversas & $\$ 480$ \\
\hline
\end{tabular}

Fuente: (AHCOR, NPM, EP. 220, 1939).

León Dereix e Hijos también se asociaron con reconocidos ganaderos de Sincelejo como Rogelio Támara y la firma Hijos de Arturo García, con quienes estableció "ganado a utilidad", un contrato donde uno de los socios colocaba los semovientes en potreros de propiedad del otro socio, cuyas ganancias, representadas en la reproducción de ganado, se repartían en partes iguales o desiguales de acuerdo a lo convenido (AHCOR, NPM, EP. 220, 1939) (Posada, 1998, pp.154-157) (Van Ausdal, 2008, pp. 82-85). Probablemente los potreros de las fértiles tierras de los Dereix representaron un atractivo para sus socios de Sincelejo, quienes vieron la oportunidad de aprovechar la experiencia de los hermanos Dereix en la cría y aumentar de esta manera su stock de ganado.

En 1943, año en que falleció León Dereix, la sociedad tuvo dos modificaciones. La primera, cuando se incorpora Marthe Dereix, esposa de León Dereix, por lo cual la sociedad cambia su razón social a Hijos de León Dereix y Compañía, con una duración de diez años, especificando nuevamente que las actividades de la sociedad descansarían sobre "La explotación de negocios de compra y venta de ganados, cría, levante y engorde de los mismos", con un capital líquido de 393.282,16 pesos, más las propiedades que se especifican en la tabla 5. La segunda, amplió las actividades de la sociedad a la "Compra y venta de maderas aserradas y en bruto, explotación y venta de productos agrícolas y en general [...] de todas aquellas operaciones que sean licitas" (AHCOR, NPM, EP. 721, 1943), como veremos en la siguiente sección del trabajo (v. Figura 5). 
Tabla 5

Propiedades aportadas como capital de Hijos de León Dereix y Compañía (1943)

\begin{tabular}{l|cc}
\hline Propiedad y/o bienes & Extensión y/o & Avalúo o valor estimado \\
\hline $\begin{array}{l}\text { La mitad proindivisa de } \\
\text { El Torno de Matamoros }\end{array}$ & SD \\
\hline Hacienda "Pasatiempo" & S.000 hectáreas & SD \\
\hline 1 casa-solar de tejas & SD & SD \\
\hline 1.414 reses hembras & SD & SD \\
\hline
\end{tabular}

Fuente: (AHCOR, NPM, EP. 561, 1943).

\subsection{Producción agrícola y maderera}

Durante las tres últimas décadas del siglo XIX el cacao despertó algún interés entre productores y empresarios agrícolas, tanto extranjeros como nacionales en el valle del río Sinú. En 1882, por ejemplo, Augusto Dangaud -un ciudadano francés que actuaba como agente comercial en Cartagena-, recibió apoyo de inversionistas de Burdeos para crear la sociedad Cacaotales de Marta Magdalena con el propósito de sembrar 100.000 árboles de cacao. La Sociedad Agrícola del Sinú, otra compañía francesa, también invirtió en sembrados de este árbol. Algunos capitales locales también incursionaron en este género: en 1893 había sembrados 350.000 árboles repartidos en una treintena de propiedades (Posada, 1998, pp. 100-101). Los hermanos Dereix no fueron ajenos al interés por el cacao. Según relata Carlos Dereix, en El Torno llegaron a tener unas 70 hectáreas sembradas de cacao cuya producción era vendida a la Compañía Colombiana de Chocolates ubicada en Medellín; el cacao era empacado en sacos que se transportaban en lanchas desde El Torno hasta Montería, y desde allí a Medellín a través de dos rutas, una aérea y otra terrestre. Esta última implicó el transporte de la carga de Montería hacia el puerto de Magangué, y luego río arriba hasta llegar a Puerto Berrio, de donde era conducido a su destino final (Ocampo, 1985, pp. 12-13). 
Figura 5. Aviso comercial de la casa Hijos de León Dereix y Compañía

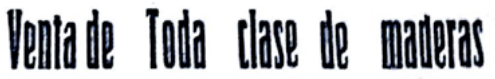

Hijos de León Dereix y Cia

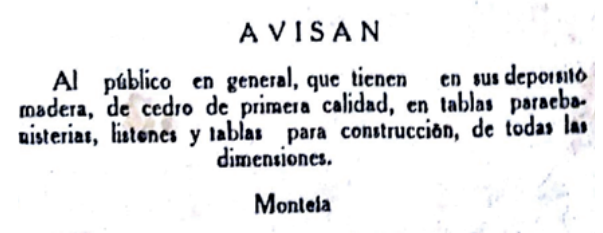

Fuente: (La Voz del Sinú, agosto 4 de 1946, p. 7).
Pese al interés por el cacao en el valle del río Sinú, su cultivo y comercialización fue limitado por varias razones. En primer lugar, la escasez de capitales y el descuido de las plantaciones fue pan de cada día, originando bajas cosechas. En segunda instancia, las inundaciones periódicas producidas por el río Sinú destruyeron no pocos árboles, paradójicamente las áreas distantes del río donde se podía sembrar cacao, tenían el agravante de que en épocas secas los árboles se morían por falta de agua (Posada, 1998, p. 101). Sin embargo, este no parece haber sido el caso de los hermanos

Dereix, quienes tenían un mercado asegurado para su producción cacaotera. Según relata Carlos Dereix

"El cacao se acabó por las enfermedades. La plaga justamente, y cuando la guerra del [19]14 al [19]18 que no había la comunicación con Europa, ni los Estados Unidos, los productos químicos para defender las plantaciones de cacao no vinieron. De manera que los cacaos perecieron [...]" (Ocampo, 1985, pp. 12-13).

Se infiere que la crisis del cacao producido en El Torno se presentó más por la coyuntura histórica de la primera guerra mundial, la cual obligó a los países que intervinieron directamente en ella a priorizar su producción y cerrar mercados, finiquitando la llegada de productos químicos al Sinú para contrarrestar las plagas y las enfermedades agrícolas que, como en el caso del cacao, eran de cierta manera el eslabón más débil en un contexto productivo marcado más por la vocación ganadera.

Por otro lado, los bosques existentes en el perímetro de El Torno fueron también objeto de explotación por Hijos de León Dereix y Compañía. En efecto, del Torno fueron talados árboles de cedro que fueron a parar a aserraderos, carpinterías y ebanisterías de Montería, las cuales ofrecían madera de caoba y cedro de buena calidad, al igual que muebles y otros enseres construidos en madera. Según Carlos Dereix, la familia también tuvo su propio aserradero en El Torno en 1944, el cual abastecía la mayoría de las ebanisterías y carpinterías de la ciudad, así como también las necesidades propias de la hacienda en materia de construcción (Ocampo, 1985, p.27) ${ }^{13}$.

13. La explotación maderera en el Alto y Medio Sinú en las dos últimas décadas del siglo XIX sentó las bases para la creación de aserríos, carpinterías y ebanisterías en Montería. En 1882 se creó La Colombie, una proyectada fábrica de papel en el Sinú, idea que pronto fue abandonada para que se fundara un aserrío en el sitio conocido como La Máquina, en el lugar donde funcionó el Club Montería (Berrocal, 1980, pp. 61-62). Se sabe que en 1929 Luis Lacharme León tenía una sociedad con Marco Aurelio Pineda, Josías Puche, José Julián Jiménez y Miguel Olivella llamada Compañía Aserradora de Montería S.A. Nueve años después, junto a Miguel Olivella, creó la sociedad Luis Lacharme y Compañía, dedicada enteramente al ramo del aserrío y la compra-venta de toda clase de madera (AHCOR, NPM, EP. 430, 1929) (AHCOR, NPM, EP. 167, 1938) (AHCOR, NPM, EP. 172, 1938). 
A finales de la década de 1940 encontramos a Hijos de León Dereix y Compañía asociándose con Tomás y Ernesto Borrero, Guillermo Lince y Eduardo Espinoza para crear la Sociedad Agrícola Dereix-Borrero y Compañía, dedicada al comercio de productos agrícolas, con capital inicial de 7.000 pesos (AHCOR, NPM, EP. 249, 1949). No se encontraron más documentos que nos permitieran rastrear el desempeño posterior de esta sociedad, pero ella reafirma la vocación empresarial agropecuaria de la familia Dereix.

\subsection{Banca, crédito, comisiones y comercio local}

En el período 1908-1910 los hermanos Octabio y León Dereix crearon la sociedad mercantil colectiva O. \& L. Dereix desde donde organizaron sus negocios, sin embargo, se tiene noticia de que antes, probablemente entre 1905 y 1906, habían fundado una sociedad que fungía como captadora de depósitos, crédito y comisiones, época que coincidió con el retiro de ambos hermanos de la Sociedad Agrícola del Sinú (Ocampo, 1985, p. 15) (López, 1986, p. 9) (Posada, 1998, p. 322). Por la seriedad con que encaró esta actividad, la sociedad mercantil se ganó el reconocimiento del comercio en Montería hasta el punto que se la llamaba el "Banco Dereix", donde se compraban y vendían letras de cambio, se recibían depósitos a la orden, préstamos, hipotecas y toda clase de comisiones que implicaron manejo de capital líquido (Berrocal, 2013) (AHCOR, NPM, EP. 136, 1910). En 1926 el Departamento de Comercio de los Estados Unidos registró en una lista de bancos colombianos a O.\& L. Dereix como una casa de banco privada (Departmen of Commerce, 1926, p. 2). Nascimento afirmó que "[...] la Casa Dereix es para el Sinú lo que el Banco Dugand para Barranquilla: una institución que hace honor a sus fundadores y casi "nacional" [...] Tanto los grandes capitalistas como los pequeños propietarios depositan allí sus fondos con toda confianza o acuden en solicitud de préstamos hipotecarios para ensanchar sus industrias" (Nascimento, 1919, pp. 25-26). Las funciones de captadora de depósitos o ahorros privados finiquitaron en 1915, probablemente porque un año después esa tarea la asumió el Banco del Sinú, donde Octabio Dereix fungió como uno de sus directores suplentes al lado de Prisciliano Cabrales y Luis Lacharme González (Nascimento, 1916, p. 17). No obstante, O.\&L. Dereix siguió ofreciendo crédito a pequeños y medianos finqueros, ganaderos y comerciantes sobre la base de hipotecas de propiedades. En efecto, al revisar la documentación notarial observamos una intensa actividad crediticia de O.\& L. Dereix entre 1908 y 1937, período en el cual otorgaron 53 créditos hipotecarios sobre posesiones rurales y propiedades urbanas, en las que el interés mensual osciló entre el 1\% y el 4\%.

Una muestra de 17 hipotecas de las 53 registradas en la Notaría Primera de Montería revela la tendencia de preferencia de hipotecas de posesiones rurales (fincas, potreros) por encima de las propiedades urbanas, aspecto que sin duda estaba relacionado con la vocación de empresarios agropecuarios de los hermanos Dereix. En 1915, por ejemplo, Alejandro Fuentes hipotecó a O \& L. Dereix por 1.284,27 pesos oro al 3 \% mensual las siguientes propiedades: "Finca nombrada La Gaita, compuesta de caucho, cacao y otros árboles frutales; finca nombrada Carrizola, compuesta de yerba pará y terreno inculto, todo con una extensión de 1.000 hectáreas; la finca nombrada Las Moncholas, de cuatro fanegas de extensión sembrada de yerba pará; un solar situado en la calle Jesús, de Montería" (AHCOR, NPM, EP. 305, 1915). Un año después Miguel Sofán, reconocido empresario y comerciante de Montería, hipotecaba a O. \& L. Dereix dos fincas en el Alto Sinú por valor de 2.371,47 pesos oro, y su hermano Antonio Sofán hizo lo mismo cuatro meses más tarde hipotecando la finca nombrada La Marsellesa por valor de 2.821 pesos oro (AHCOR, NPM, EP. 71 y 220, 1916). Cuatro años después, en 1918, Manuel Vicente Jiménez hipotecó a O. \& L. Dereix la finca llamada Palmira, ubicada en las mancomunidades de 
Negrete y Hamaca, por valor de 1.500 pesos oro por el término de un año al $2 \%$ mensual de intereses (AHCOR, NPM, EP. 324, 1924). En 1919 Cristóbal Rosso hipotecó a O. \& L. Dereix dos posesiones llamadas Jaraguay y Los Limones, en jurisdicción de Montería, constituidas por casa de habitación y sembradas de yerba pará, por valor de 2.000 pesos oro al término de 18 meses al interés del 2\% (AHCOR, NPM, EP. 258, 1919). Este último año Teófilo Gómez hipotecó a O. \& L. Dereix los potreros Delirio y Buenos Aires, cercanos a Montería, por valor de 5.000 pesos oro por el término de 33 meses, pagaderos por trimestres a razón de 11\%2\% mensual (AHCOR, NPM, EP. 276, 1919).

Tierras y predios ubicados en jurisdicciones circunvecinas a Montería como Cereté, San Pelayo y San Carlos de Colosiná también fueron objeto de hipoteca a O. \& L. Dereix. Así, por ejemplo, en 1918 Pedro Antonio Ayala hipotecó el potrero llamado Las Lauras, en jurisdicción de Cereté, por valor de 500 pesos oro por el término de un año al interés del 2\% mensual; un año después Marceliano Pinedo hipotecó una posesión en el distrito de San Carlos por valor de 1.000 pesos oro por el término de 18 meses al interés del 1 $1 / 2 \%$ mensual pagaderos por trimestre, y en 1923 Orosman Soto hipotecó un terreno compuesto por un potrero y cultivos de pasto pará en el lugar nombrado Bocagrande, en jurisdicción de San Pelayo, por valor de 1.000 pesos oro por el término de seis meses, con interés de $1 \frac{1}{2}$ mensual pagaderos por trimestre (AHCOR, NPM, EP. 486, 1918) (AHCOR, NPM, EP. 706, 1919) (AHCOR, NPM, EP. 264, 1923).

De otra parte, los créditos hipotecarios también contemplaron el pago de deuda y de intereses con producciones agrícolas, particularmente en pastos para alimentar el ganado y en ocasiones en fuerza de trabajo. En 1918, por ejemplo, Pedro Junieles hipotecó a O. \& L. Dereix una finca sembrada de pasto pará, con casa de habitación, ubicada en tierras baldías, por valor de 250 pesos oro, los cuales serían pagados con el pasto producido en 40 hectáreas de tierra ubicadas en El Torno de Matamoros (AHCOR, NPM, EP. 420, 1918). Similar crédito se otorgó a Nicolás Muñoz, quien en garantía hipotecó dos fincas en jurisdicción de Montería, cuyo capital e intereses pagaría con la producción de pastos sembrados en otras 40 hectáreas en El Torno (AHCOR, NPM, EP. 457, 1918). De otro lado, Miguel Ángel Zúñiga hipotecó a O. \& L. Dereix un solar ubicado en la calle de Jesús, de Montería, por valor de 110 pesos oro por el término de dos años, sin intereses, deuda que debía pagarse en fuerza de trabajo personal a los hermanos Dereix a razón de 50 centavos por día, sin alimento, durante el tiempo pactado para cancelar la deuda (AHCOR, NPM, EP. 575, 1919).

Las comisiones desempeñaron un papel importante en las actividades de O. \& L. Dereix, hasta el punto que en 1916 se creó al interior de la sociedad una sección de comisión e importaciones, la cual se ocupó de la introducción al país de maquinaria industrial vinculada a los trabajos del campo y los transportes, vinos, muebles, entre otros géneros, traídos de Europa y de los Estados Unidos. O.\& L. Dereix poseía un catálogo donde informaba de los ramos del comercio y los productos que tenían a su disposición en los mercados exteriores; en una ocasión, por ejemplo, llevaron al municipio de Montería una verja de hierro, lámparas y sillas para el parque central de la ciudad, así como arados de discos utilizados por los agricultores en labores de desmonte y limpieza de ciénagas, caños y humedales (Nascimiento, 1919, p. 26). Los contactos directos e indirectos con casas comerciales de Europa y Estados Unidos le permitieron manejar información sobre mercados y precios, lo cual posibilitó su intermediación en la introducción y circulación de mercaderías y bienes. Así, por ejemplo, O.\& L. Dereix se convirtió en sub-agente distribuidor de las vacunas líquidas Pasteur para el ganado, importadas directamente desde Francia, y solicitaban a las casas comerciales de Cartagena otros productos de 
consumo que no podían producirse o encontrarse en Montería tales como barniz, pimienta picante y azufre, encargados a la casa comercial Ganem \& Compañía (FiatLux, enero 9 de 1927, p. 3) (AHCOR, NPM, EP. 51, 1935). Restrepo y Rodríguez sostienen, para otro contexto, que los comisionistas actuaban en distintos tipos de operaciones que requerían de contactos con clientes y mercados, lo que devenía en el manejo de la información comercial y legal que los posicionaba como portadores de un saberhacer, necesarios para articular mercados y producción (2003, pp. 29-32).

Por otro lado, el comercio al detal también hizo parte de las actividades económicas de los hermanos Dereix, ofreciendo en su Gran Almacén de Novedades en Montería una línea miscelánica de géneros que incluyeron telas, calzados, utensilios de trabajo para el campo y otros artículos de consumo cotidiano. Para la época un almacén no tenía mucha diferencia con una tienda, es decir, un establecimiento de comercio pensado para el pequeño consumo tanto para artículos de diario como para ocasiones especiales.
Figura. 6. Aviso comercial

de la Casa O. y L. Dereix

EL GRAN ILMACEN DE NOVEDADSS DP

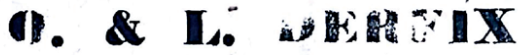

()frece a su numerosá olientela bellísimo - surtido de telas finas. oalzado $\bar{y}$ artículos para regalos etc etc.

Haga una visita al almacén y se convencerá de la gran rebaja de precios.

Fuente: (Fiat- Lux, n 155, Montería, 30 de mayo de 1926, p. 3).

\subsection{Acciones en compañías y sociedades}

Los hermanos Octabio y León Dereix también incursionaron en la conformación de compañías para la explotación minera, así como en la compra de acciones en compañías asociadas a la exploración y explotación petrolera. Así, en 1922 junto a Enrique Gómez Pérez, Alberto Grandet, Antonino Lacharme y Eusebio Pineda conformaron la Compañía Minera del Alto Sinú, que se centraría en la explotación de las minas de oro y plata que se encontrasen en predios de su dominio, el cual comprendía las propiedades de Pasatiempo, San Jerónimo, La Mina, El Conejo y La Palma. La compañía tendría una duración de 20 años y su capital inicial fue de 2.000 pesos oro, aportando O. \& L. Dereix a Pasatiempo como parte del capital que le correspondía (AHCOR, NPM, EP. 115, 1922). Ocho años más tarde, O. \& L. Dereix, presidida ya para la época por León Dereix, en compañía de José Samudio, representante de la firma García \& Samudio, de Sincelejo, crearon la Compañía del Automóvil Moderno O. \& L. Dereix, dedicada a la "Compra y venta de automóviles, camiones, chasis y demás útiles y repuestos de la marca Ford", con capital de 5.000 pesos oro (AHCOR, NPM, EP. 30, 1930). Es probable que esta compañía hubiese obtenido la exclusividad de importar vehículos y autopartes de la mencionada Ford para la región de las sabanas, motivada por el interés del auge que estaban tomando los transportes terrestres ante las crecientes dificultades de navegación del río Sinú (El Fígaro, 1946, noviembre 3, p. 8, cit. en Díaz, 1994, pp. 141-142). 
En 1939, una vez disuelta O. \& L. Dereix, la nueva sociedad creada, León Dereix e Hijos, reportó en su conformación acciones y bonos invertidos en compañías relacionadas con la exploración y explotación minera (Tabla 6).

Tabla 6

\section{Acciones y bonos de León Dereix e Hijos en compañías energéticas}

\begin{tabular}{ccc}
\hline Compañía & Acciones y/o bonos & Avalúo \\
\hline $\begin{array}{c}\text { Compañía de } \\
\text { Petróleo de Sahagún }\end{array}$ & 200 acciones & $\$ 500$ \\
\hline $\begin{array}{c}\text { Compañía de Petróleo } \\
\text { y Carbón del Sinú y Sabanas }\end{array}$ & 21 acciones & $\$ 366,28$ \\
\hline $\begin{array}{c}\text { Compañía Colombiana } \\
\text { de Mutualidades }\end{array}$ & 14 bonos & $\$ 100$ \\
\hline
\end{tabular}

Fuente: (AHCOR, NPM, EP. 220, 1939).

La Compañía de Petróleo y Carbón del Sinú y Sabanas, en la que León Dereix e Hijos poseía 21 acciones, fue presidida por Francisco Burgos Rubio y Prisciliano Cabrales, con sede en Ciénaga de Oro, la cual incorporó como parte del capital inicial los bienes de la sociedad Manuel Burgos \& Co. y del mencionado Prisciliano Cabrales (Ripoll, 1999, p. 56) (Durán, 2017, p. 13).

\section{CONCLUSIONES}

Este artículo analizó las actividades empresariales y comerciales de la familia Dereix en el valle del río Sinú desde finales del siglo XIX hasta la primera mitad del siglo XX, cuyo caso resulta pertinente por dos razones. En primer lugar, porque no se trata de la gran familia empresaria ${ }^{14}$ vinculada con el poder político, sino de una familia de inmigrantes franceses que llegó al país jalonada por la presencia de la Compañía Francesa del Río Sinú, la cual supo adaptarse al contexto fronterizo de la región para crear una empresa familiar que perduró durante dos generaciones. En segunda instancia, porque su experiencia empresarial permite comprender de mejor manera las lógicas que guiaron

14. El concepto de familia empresaria hace referencia a familias con diversos grados de parentesco sanguíneo o espiritual, las cuales durante varias generaciones realizan inversiones productivas en distintos negocios en los que no necesariamente se controla ni propiedad ni gestión, con el objetivo de hacer permanecer los valores y la continuidad de la familia en el tiempo (Fernández y Lluch, 2015, p. 19). Una experiencia histórica de grandes familias empresariales en México puede verse en (Cerruti, 2016, pp. 25-66) 
la organización de las actividades empresariales de unos individuos que, como los hermanos Dereix, constituyeron lo que Dávila llama la vanguardia de una clase social en ascenso que se identificó con el desarrollo capitalista del país y poseía un ámbito de acción nacional (Dávila, 2013, p. 19).

En ese orden de ideas, se pueden identificar dos momentos en la experiencia empresarial y comercial de la familia Dereix. Un primer momento marcado por la llegada de la familia a Montería, en un contexto de expansión de la frontera ganadera, agrícola y forestal, y la disponibilidad de tierras baldías que brindaron oportunidades a empresarios, comerciantes y colonos para establecerse en el Medio y Alto Sinú. Una década en la administración de la Sociedad Agrícola del Sinú posibilitó a los hermanos Dereix reconocer el potencial agropecuario y forestal de la zona, así como una dinámica de intercambios en aumento que centró sus operaciones en la ciudad de Montería. Allí, una vez salieron de la administración de la Sociedad Agrícola del Sinú, crearon entre 1908 y 1910 la sociedad mercantil colectiva O. \& L. Dereix, desde donde organizaron negocios especulativos relacionados con captación de ahorros, créditos, compra y venta de letras de cambio, comisiones por distribución e importación de géneros varios y el comercio local. En esta misma época los hermanos Dereix comienzan a adquirir tierras en el área rural para convertirlas en hatos y haciendas ganaderas, al igual que potreros y pastizales para el control y alimento del ganado que poco a poco iban adquiriendo. Podemos afirmar que en este primer momento de la vida económica de los hermanos Dereix se presentó la acumulación de sus capitales, los cuales posteriormente les permitieron diversificar y tecnificar sectorialmente sus inversiones en el ámbito empresarial.

El segundo momento está marcado por la partida de Octabio Dereix hacia Francia en 1928 y la posterior disolución de O. \& L. Dereix en 1939, quedando al frente de los negocios León Dereix ${ }^{15}$. Este último había creado en 1930, junto a sus hijos, la sociedad León Dereix e Hijos, la que después tuvo un ajuste y pasó a llamarse Hijos de León Dereix \& Co. una vez fallecido León D. en 1943 e incorporada su esposa Marthee Conrad de Dereix. Esta etapa está marcada por la orientación empresarial que tomaron los negocios de la familia, caracterizados por la diversificación de las inversiones y la tecnificación de los procesos de producción desarrollados desde la hacienda El Torno de Matamoros. Por otro lado, no menos importante eran la conformación y compra de acciones y bonos en empresas o compañías mineras que resultaban importantes en activos de renta fija, particularmente las acciones invertidas en la naciente actividad de exploración y explotación petrolera que despertó el interés de empresarios y compañías nacionales y extranjeras desde finales del siglo hasta mediados del siglo XX.

Los hermanos Octabio y León Dereix y luego los sucesores de este último supieron leer el contexto fronterizo del Sinú, identificando oportunidades de negocios y empresas en una región que apenas se abría a la incursión del capitalismo, calculando los riesgos para construir lógicas de prácticas económicas sobre la que descansaron sus actividades. Dávila (271), ha mostrado como la conducta económica de los empresarios descansa sobre su papel innovador, las alertas que construyen para observar las oportunidades

15. A su regreso de Francia, probablemente entre 1936 y 1937, Octabio Dereix realizó individualmente y por poco tiempo algunos negocios de compra de tierras en la jurisdicción de Montería, pero posteriormente se residenció en Barranquilla donde falleció el 22 de agosto de 1955. 
del mercado, así como el manejo de la incertidumbre y el riesgo. Desde estas variables construye creativamente sus respuestas al contexto. Otros casos de negociantes y empresarios del valle del río Sinú como el de los hermanos Dereix, permitirán profundizar sobre la aptitud y la mentalidad empresarial de hombres y mujeres que supieron adaptar y adaptarse a un medio que en no pocas ocasiones resultaba difícil y precario.

\section{REFERENCIAS BIBLIOGRÁFICAS.}

Álvarez, J. (2016). Mercado, ganado y territorio. Haciendas y hacendados en el Oriente y el Magdalena Medio antioqueños (1920-1960). Medellin, Universidad de Antioquia/Universidad Pontificia Bolivariana.

American Lumbermen (1905). The Personal History and Public and Business Achievements of One Hundred Eminent Lumbermen of United States. Chicago: The American Lumbermen.

Archivo Histórico de Córdoba (AHCOR), Fondo Notaría Primera de Montería: Escrituras públicas 1908-1950.

Berrocal, J. (1980). La colonización antioqueña en el departamento de Córdoba. Montería: Gráficas Corsa.

Bonet, J. (1999). “El ganado costeño en la feria de Medellín (1950-1997)”. Aguaita, 2, 48-56.

Burgos, R. [1965] (2000). El general Burgos. Cartagena: Gobernación de Bolívar/Instituto Internacional de Estudios del Caribe.

Cabrales, P. (1916). "Riqueza minera del Sinú. Algo sobre su historia. Generalidades". En Nascimento, A. (Editor). Guía Ilustrada del Sinú. Montería: Tipografía El Esfuerzo.

Carlos Dereix (1985). Entrevista realizada por Gloria Isabel Ocampo.

Cerruti, M. (2016). "Elites, regiones económicas y empresariado. El gran empresariado de Monterrey (1848-2007)". En López, J. y Cerruti, M. (Editores). Historia económica y empresarial. México-Colombia s. XIX-XX. Medellín: Fondo Editorial Universidad EAFIT/Universidad Autónoma de Nuevo León.

Dávila, C. (2013). Empresariado en Colombia: perspectiva histórica y regional. Bogotá: Universidad de los Andes.

Department of Commerce of United States of America, 1926.

Díaz, F. (1994). Breve historia de Santa Cruz de Lorica. Bogotá: Tercer Mundo Editores, 1994.

Durán, X. [2011] (2017). “Petróleo en Colombia,1900-1950: especuladores y empresas multinacionales”. En Benavides, J. (Editor). Ecopetrol: sesenta años de historia (1951-2011). Bogotá: Ecopetrol/ Universidad de los Andes.

El Fígaro, Cartagena, 1946: noviembre 3.

Exbrayat, J. (1939). Reminiscencias monterianas. Montería: El Esfuerzo.

Exbrayat, J. [1971] (1994). Historia de Montería. Montería: Alcaldía Mayor. 
Fernández, P. y Lluch, A. (Editoras) (2015). "Introducción”. En Familias empresarias y grandes empresas familiares en América Latina y España. Una visión de largo plazo. Madrid: Fundación BBVA.

Fiat-Lux. Semanario de Información y Variedades, Montería, 1926: 13 de junio; 12 de septiembre; 21 de noviembre; 1926: 30 de mayo.

González, J., et. al. (1986). La planificación del desarrollo agropecuario. México: Siglo XXI.

Instituto Geográfico Agustín Codazzi (IGAC) (1992). Córdoba. Características geográficas. Bogotá: IGAC.

La Voz del Sinú, Montería, 1946: 4 de agosto.

LeGrand, C. [1984] (2016). Colonización y protesta campesina en Colombia (1850-1950). Bogotá: Universidad de los Andes/Universidad Nacional de Colombia/Centro de Investigación y Educación Popular.

López, A. (1986). "Los sinuanos frente a la Penetración Francesa (1844-1915)”. La Revista de la Academia de Historia de Córdoba, 3, 8-11.

Nascimento, A. (Edit.) (1916). Guía Ilustrada del Sinú. Montería: Tipografía El Esfuerzo.

Nascimento, A. (Edit.) (1919). Guía Comercial del Sinú. Montería: Tipografía Mendoza.

Ocampo, G. (2007). La instauración de la ganadería en el valle del Sinú: la hacienda Marta Magdalena, 1881-1956. Bogotá: Instituto Colombiano de Antropología e Historia/ Universidad de Antioquia.

Ocampo, J. [1984] (2013). Colombia y la economía mundial 1830-1910. Bogotá: Universidad de los Andes.

Palacios, N. (2009). La utopía de un paraíso. Los franceses en Colombia. Bogotá: Embajada de Francia en Colombia/Planeta.

Parsons, J. (1952). “The Settlement of The Sinu Valley of Colombia”. Geographical Review, 1 (46), 67-86.

Parsons, J. (1996). Urabá, salida de Antioquia al mar. Geografía e historia de la colonización. Bogotá: Banco de la República/El Áncora Editores.

Posada, E. (1998). El Caribe colombiano. Una historia regional (1870-1950). Bogotá: El Áncora/Banco de la República.

Poveda, G. (2013). Población y censos en Colombia. Desde la conquista hasta el siglo XXI. Medellin: Ediciones Unaula.

Quintero, E. (1922). "Guía Comercial, Geográfica e Histórica del Alto y Bajo Sinú". En Striffler, L. El rio Sinú (Aumentado con una relación histórica, geográfica y comercial de las poblaciones del Alto y Bajo Sinú). Cartagena: Tipografía de El Anunciador.

Restrepo, J. y Rodríguez, M. (2003). La actividad comercial y el grupo de comerciantes de Cartagena a finales del siglo XIX. Bogotá: Universidad de los Andes/Serie Historia del Desarrollo Empresarial, 6.

Ripoll, M. (1999). La actividad empresarial de Diego Martínez Camargo, 1890-1937. Cartagena: Cuadernos de Historia Económica y Empresarial, $\mathrm{N}^{\circ} 2$, Centro de Investigaciones Económicas del Caribe colombiano. 
Striffler, L. (1922). El Rio Sinú. Cartagena: Tipografía El Anunciador.

Tovar, H. (1997). "Los baldíos y el problema agrario en la Costa Caribe de Colombia (1830-1900)". Fronteras, 1 (1), 35-55.

Uparela, F. (2004). Historia de Planeta Rica. Los pioneros. Los raicilleros 1885-1900. Planeta Rica (Córdoba): Alcaldía Municipal.

Van Ausdal, S. (2008). Un mosaico cambiante. Notas sobre una geografía histórica de la ganadería en Colombia, 1850-1950. En: A. Flórez (Editor.). El poder de la carne. Historias de ganaderías en la primera mitad del siglo XX en Colombia (pp. 48-117). Bogotá: Universidad Javeriana.

Viloria, J. (2001). Ganaderos y comerciantes de Sincelejo 1880-1920. Cartagena: Banco de la República, Cuadernos de Historia Económica y Empresarial, 8. 